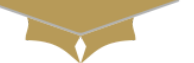

MEDRESEARCH

www.medresearch.in

\title{
A study to evaluate the functioning of primary health care workers at the village level in rural Amritsar, Punjab, India
}

\author{
Bakshi R. ${ }^{1}$, Singh T. ${ }^{2 *}$, Kaur J. ${ }^{3}$, Arora A. ${ }^{4}$, Verma R. ${ }^{5}$ \\ DOI: https://doi.org/10.17511/ijphr.2019.i5.05
}

\footnotetext{
${ }^{1}$ Ritika Bakshi, Tutor/Demonstrator, Department of Community Medicine, Government Medical College, Amritsar, Punjab, India.

2* Tejbir Singh, Associate Professor, Department of Community Medicine, Government Medical College, Amritsar, Punjab, India.

3 Jasleen Kaur, Assistant Professor, Department of Community Medicine, Government Medical College, Amritsar, Punjab, India.

${ }^{4}$ Ankit Arora, Senior Resident, Department of Pharmacology, Lady Hardinge Medical College, New Delhi, , India.

$\mathbf{5}$ Richa Verma, Ex Junior Resident, Department of Community Medicine, Government Medical College, Amritsar, Punjab, India.
}

\begin{abstract}
Background: About $68 \%$ of the total population lives in rural India; which makes it important to focus on rural areas. The only way to avoid poverty in these areas; induced by healthcare expenditures, is to strengthen the public healthcare system. Here the role of primary health care workers becomes imperative in order to facilitate the community participation and to address various social and cultural barriers in the etiology of health and disease. Methods: The present cross-sectional study was carried out in village Nagkalan, Amritsar, where the eldest adult member present in the house at the time of the visit was interviewed. Every house of the village was visited during the period of January 2017 to December 2017, and a total of 1123 families were included in the final analysis. Thereafter, data was compiled and analyzed. Results: Majority of the families $(72.7 \%)$, were visited by the ASHA occasionally; whereas $13.7 \%$ were never visited by her. Out of 969 families visited by ASHA worker, $73.4 \%$ were visited for imparting knowledge regarding immunization services while $29.9 \%$ and $14.1 \%$ were visited for maternal and child health services and treatment of minor ailments respectively. The association between socio-economic status and home visits performed by ASHA was found to be statistically significant. The study also revealed that only $8.3 \%$ and $1 \%$ of the families were ever visited by the female and male multipurpose health workers respectively. Conclusion: The present study concluded that the home visits were mostly carried out by the ASHA workers (that too on occasional basis) while the contribution made by the multipurpose health workers was very less. The main reasons cited for the visits by ASHA worker were immunization of children, $\mathrm{MCH}$ related activities and for the treatment of minor ailments.
\end{abstract}

Keywords: ASHA, Multipurpose Health Workers, Anganwadi

Corresponding Author

Tejbir Singh, Associate Professor, Department of Community Medicine, Government Medical College, Amritsar, Punjab, India. Email: drtejbirsingh56@gmail.com

\section{How to Cite this Article}

Bakshi R, Singh T, Kaur J, Arora A, Verma R. A study to evaluate the functioning of primary health care workers at the village level in rural Amritsar, Punjab, India. Public Health Rev Int J Public Health Res. 2019;6(5):207-213.

Available From

https://publichealth.medresearch.in/index.php/ijphr/ article/view/121
Manuscript Received 2019-10-10

Conflict of Interest No

Review Round 1
2019-10-20
Funding
Nil

Review Round 2
2019-10-26
Ethical Approval
Yes

Review Round 3

Plagiarism X-checker $6 \%$
To Browse

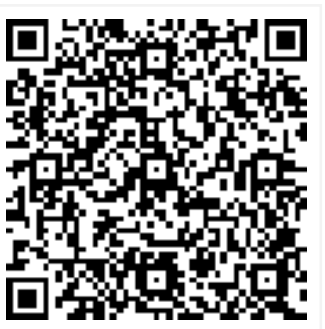

() 2019 by Ritika Bakshi, Tejbir Singh, Jasleen Kaur, Ankit Arora, Richa Verma and Published by Siddharth Health Research and Social Welfare Society. This is an Open Access article licensed under a Creative Commons Attribution 4.0 International License https://creativecommons.org/licenses/by/4.0/ unported [CC BY 4.0]. 


\section{Introduction}

The primary health care workers have been conceptualized as social and cultural intermediaries strengthening the interface between the existing health system and the community. Their role is to facilitate the community participation and take necessary actions to address and remove social and cultural barriers that lead to poor health [1].

The Accredited Social Health Activist (ASHA) was introduced by the National Rural Health Mission (NRHM) in 2005. Each ASHA covers a population of 1000, and fulfills various different roles. First, ASHAs function as a 'link worker', a bridge between the rural and vulnerable population on one hand and primary health service centres on the other. Second, ASHAs function as a 'service extension worker', whereby they are trained and provided with a kit that includes commodities such as condoms, oral contraceptive pills, delivery kits and simple life saving drugs. Third, they are the 'health activists' in the community who create awareness on health and its social determinants and mobilize the community towards local health planning and increased utilization and accountability of the existing health services [2].

The multi-purpose health worker female works at the level of subcentres; towards maternal and child health, family planning, health and nutrition education, for maintaining environmental sanitation, immunization for the control of communicable diseases, treatment of minor injuries, and first aid in emergencies and disasters. In remote areas, such as hilly and tribal areas where transport facility is likely to be poor, MPHW (F) are also required to conduct home deliveries for women [3].

Multipurpose health worker (male) have been recognized as critical to the achievement of universal health coverage by means for continuum of care. Some of the significant aspects of service delivery by MPHW Males are i) general curative care involving medicine distribution through home visits, ii) counselling male members of the community about health, iii) collection of blood sample for smear preparation (specially for malaria suspected cases- the beat program), iv) geriatric care and counselling related with non-communicable diseases, $v$ ) organizing and mobilizing community for health camps and, vi) co-ordination with health workers on nutrition and health day for weight and height check- up of children.
But in practice, there is less emphasis on recruitment of male-MPHWs. Scarcity of male MPHWs has caused challenges not only in implementation of national health programs but also increased responsibilities of female-MPHWs. Also, there is inefficient utilization of existing maleMPHWs [4].

Another important source of primary health care workers is the Integrated Child Development Scheme (ICDS) program, under the Ministry of Women and Child Development, which is the world's largest community based outreach program, offering a package of health, nutrition and educational services to the children below six years, pregnant and nursing mothers and adolescent girls, through its anganwadi centres [5].

An Anganwadi is the focal point for the delivery of ICDS services which directly and indirectly affect health, and hence must work in coordination with the ASHA and the MPHWs in order to effectively deliver the package of services to the beneficiaries.

This study was therefore done because primary health care is the frontline of health care system to keep people well and improve their quality of life, and about $68 \%$ of the total population lives in rural India; which makes it imperative to focus on rural areas.

The only way to avoid poverty, induced by healthcare expenditures, is to strengthen the public healthcare system by making the services available and accessible to all, by promoting the utilization of existing health services; which can be further achieved with the help of community health workers who interact with the community at the grass root level and understand their health needs and demands.

\section{Materials and Methods}

\section{Study design: Cross- Sectional}

Study area: Village Nagkalan, the rural field practice area of Department of Community Medicine, Government Medical College, Amritsar

Study population: All families of the village Nagkalan.

Study period: January 1, 2017 to December 31, 2017

Study sample: 1171 families residing in the village; out of which 29 families were not available 
(Their houses were permanently locked) and 19 families were non-cooperative. Rest 1123 families were interviewed.

Exclusion criteria: 1. Families who did not give consent for the study. 2. Those houses which were found locked even after the third visit.

Study tool: Semi- structured and predesigned questionnaire

Methodology: This cross-sectional study was conducted in village Nagkalan, the rural field practice area of Department of Community Medicine, Government Medical College, Amritsar, extending from the period of 1st January 2017 to 31st December 2017. After explaining the purpose of the study; written informed consent was obtained from the respondents.

The eldest adult member of the family present in the house at the time of the visit, served as the respondent and interviewed using a semi-structured and predesigned questionnaire at their place of residence. All questions were asked in the vernacular language of the respondent. A total of 1123 families were included in the final analysis. Criteria for socio-economic status was taken according to Modified Kuppuswamy Scale (2017).

Statistical analysis: The data thus collected was compiled and analyzed by using Microsoft Excel, and chi square test was used as test of significance.

Ethical Approval: Institutional Ethics Committee, Government Medical College, Amritsar.

Research Objective: To study regarding the availability and utilization of primary health care workers (ASHA, multipurpose health workers and Anganwadi) in village Nagkalan, district Amritsar, Punjab.

\section{Results}

The present study revealed that out of 1123 families, more than half (64.8\%) belonged to upper lower socio-economic status according to modified kuppuswamy scale (2017). 17.2\%, 16.0\% and $1.8 \%$ belonged to upper middle, lower middle, lower categories respectively, whereas only $0.2 \%$ belonged to upper socio-economic status (Table 1 ).

Table-1: Distribution of families according to their socio- economic status $(n=1123)$ (Modified Kuppuswamy Scale 2017).

\begin{tabular}{|l|l|l|}
\hline Upper & 2 & 0.2 \\
\hline Upper middle & 193 & 17.2 \\
\hline Lower middle & 180 & 16.0 \\
\hline Upper lower & 728 & 64.8 \\
\hline Lower & 20 & 1.8 \\
\hline Total & 1123 & 100 \\
\hline
\end{tabular}

Table-2: Distribution of families according to the frequency of visits by the ASHA $(n=1123)$.

\begin{tabular}{|l|l|l|}
\hline \multicolumn{1}{|c|}{ Response } & \multicolumn{1}{c|}{ Number } & \multicolumn{1}{c|}{ Percentage (\%) } \\
\hline Monthly & 38 & 3.4 \\
\hline Every two months & 114 & 10.2 \\
\hline Occasionally & 817 & 72.7 \\
\hline Never & 154 & 13.7 \\
\hline Total & 1123 & 100 \\
\hline
\end{tabular}

Table-3: Distribution of families according to the purpose of visit by ASHA (multiple response allowed) $(n=969)$

\begin{tabular}{|l|l|l|}
\hline \multicolumn{1}{|c|}{ Response } & Number & Percentage (\%) \\
\hline Immunization & 711 & 73.4 \\
\hline MCH services & 290 & 29.9 \\
\hline Treatment of common diseases & 137 & 14.1 \\
\hline Provision of ORS, IFA, OCP's and condoms & 112 & 11.6 \\
\hline Prevention of local diseases & 70 & 7.2 \\
\hline Diet and nutrition & 44 & 4.5 \\
\hline Any other & 202 & 20.8 \\
\hline
\end{tabular}

Table-4: Distribution of families according to visits by ASHA in relation to their socioeconomic status.

\begin{tabular}{|l|l|l|l|}
\hline \multicolumn{1}{|c|}{ Response } & \multicolumn{1}{c|}{ Lower } & \multicolumn{1}{c|}{ Middle and upper } & \multicolumn{1}{c|}{ Total } \\
\hline Visit & 701 & 268 & 969 \\
\hline Did not visit & 47 & 107 & 154 \\
\hline Total & 748 & 375 & 1123 \\
\hline
\end{tabular}

Chi square 104.5, p value< 0.05; statistically significant

In the present study it was observed that, majority of the respondents $(72.7 \%)$, were visited by the ASHA occasionally. 38 (3.4\%) and 114 (10.2\%) reported that they were visited by ASHA monthly and once in every two months respectively.

$154(13.7 \%)$ however responded that they were never visited by the ASHA (Table 2). Out of 969 families visited by ASHA worker, 711(73.4\%) were visited for imparting knowledge regarding immunization services while 290 (29.9\%) and 137 $(14.1 \%)$ respondents reported that ASHA worker visited them for maternal and child health services and treatment of minor ailments respectively.

$11.6 \%$ were visited by ASHA for distribution of ORS, iron and folic acid tablets, contraceptives etc; 
7.2\% for imparting knowledge regarding prevention of local diseases, $4.5 \%$ for advice on diet and nutrition and $20.8 \%$ for other health related activities (Table 3). It was observed that the association between socio-economic status and house to house visits performed by the ASHA was found to be statistically significant (Table 4).

Table-5: Distribution of families according to frequency of visits by the MPHW (F) $(N=1123)$.

\begin{tabular}{|l|l|l|}
\hline \multicolumn{1}{|c|}{ Response } & \multicolumn{1}{c|}{ Number } & \multicolumn{2}{c|}{ Percentage (\%) } \\
\hline Occasionally & 93 & 8.3 \\
\hline Never & 1030 & 91.7 \\
\hline Total & 1123 & 100 \\
\hline
\end{tabular}

Table-6: Distribution of families according to the purpose of visit by the MPHW(F) (multiple response allowed) $(n=93)$

\begin{tabular}{|l|l|l|}
\hline \multicolumn{1}{|c|}{ Response } & Number & \multicolumn{1}{|c|}{ Percentage (\%) } \\
\hline MCH & 92 & 99.9 \\
\hline Family planning counselling & 82 & 88.2 \\
\hline Immunization & 77 & 82.8 \\
\hline Birth/ death registration & 50 & 53.8 \\
\hline
\end{tabular}

Table-7: Distribution of families according to frequency of visits by MPHW (M) $(n=1123)$

\begin{tabular}{|l|l|l|}
\hline \multicolumn{1}{|c|}{ Response } & \multicolumn{1}{c|}{ Number } & \multicolumn{1}{c|}{ Percentage (\%) } \\
\hline Occasionally & 11 & 1.0 \\
\hline Never & 1112 & 99.0 \\
\hline Total & 1123 & 100 \\
\hline
\end{tabular}

Table-8: Distribution of respondents regarding awareness about existence of anganwadi centre in the village.

\begin{tabular}{|l|l|l|}
\hline \multicolumn{1}{|c|}{ Response } & \multicolumn{1}{c|}{ Number } & Percentage (\%) \\
\hline \multicolumn{2}{|l|}{ Heard the name $(n=1123)$} & 99.1 \\
\hline Yes & 1113 & 0.9 \\
\hline No & 10 & 100 \\
\hline Total & 1123 & 69.4 \\
\hline Knew the location $(n=1113)$ & 772 & 30.6 \\
\hline Yes & 341 & 100 \\
\hline No & 1113 & \\
\hline Total &
\end{tabular}

Table-9: Distribution of respondents regarding food provision at the anganwadi centre $(n=772)$

\begin{tabular}{|l|l|l|}
\hline \multicolumn{1}{|c|}{ Response } & \multicolumn{1}{c|}{ Number } & \multicolumn{1}{c|}{ Percentage (\%) } \\
\hline Once in 3 months & 12 & 1.6 \\
\hline Once in 6 months & 137 & 17.7 \\
\hline Once yearly & 92 & 11.9 \\
\hline Only Occasionally & 531 & 68.8 \\
\hline Total & 772 & 100 \\
\hline
\end{tabular}

In the present study, out of 1123 families, only 93 $(8.3 \%)$ families were visited by the MPHW(F) on occasional basis. Rest of the 1030 families (91.7\%) were never visited by the MPHW(F) (Table 5).

Out of the 93 families visited by $\operatorname{MPHW}(F), 92$ $(99.9 \%)$ were visited for Mother and Child Health $(\mathrm{MCH})$ related activities, $82(88.2 \%)$ for family planning advice, 77 (82.8\%) for immunization related activities, and 50 families (53.8\%) for birth/ death registration (Table 6 ).

Also, only 11 families (1.0\%) were ever visited by the MPHW(Male). Rest of the 1112 families (99.0\%) reported that they were never visited by the MPHW(Male) (Table 7).

The study further revealed that out of total 1123 families, 1113 (99.1\%) of them were aware about the existence of anganwadi centres in their village. Out of those who knew about the anganwadi centre (1113), 772 (69.4\%) ever visited and were able to correctly tell about the location of the anganwadi centre (Table 8).

It was also observed that out of those who ever visited the anganwadi centre (772), majority of them $(68.8 \%)$, reported that the food availability at the centre was occasional and mostly irregular.

$92(11.9 \%), 137(17.7 \%)$, and $12(1.6 \%)$ said that the workers distributed food items to them once yearly, once in 6 months and once in three months respectively (Table 9 ).

\section{Discussion}

In the present study, majority of the respondents $817(72.7 \%)$ were visited by the ASHA occasionally, while 154 families (13.7\%) were never visited by the ASHA. The possible reason for less or occasional visits by the ASHA in the present study could be that one of the main motivating factors for ASHA is the financial incentives which they feel is insufficient and not being provided for each and every service rendered by them; due to which they get demotivated.

Also, presence of many private clinics in the village providing round the clock services make them a preferred choice for the people. According to a study done in rural part of Haryana by Garg et al (2015), majority of the ASHAs (71.66\%) were not satisfied with their incentives and there was a general demand for increase in salary and incentives [6]. 
A study done by Bajpai et al in states of Rajasthan, Bihar, Uttar Pradesh and most parts of Chattisgarh in 2011 showed that $90 \%$ of ASHA demanded regular salary with incentives [7].

In a study by Singh et al (2010) in rural Lukhnow, it was found that ASHAs were able to connect with the community and convince women to utilize antenatal and postnatal services [8]. According to NFHS 4, there were $89.3 \%$ fully immunized children in the age group of 12-23 months in Punjab [9] and $91.9 \%$ in Amritsar district [10]. The present study revealed similar results where the ASHA worker visited $73.4 \%$ of the houses for immunization related activities showing that more importance is given to free immunization services provided by the government. However, coverage for mother and child health related $(\mathrm{MCH})$ services was only $29.9 \%$, probable reason could be the irregular visits by the ASHA worker and round the clock availability of private health clinics in the village.

A study done by Kaur et al in rural parts of Amritsar in 2015 showed that, $22 \%$ of the total families were ever visited by MPHW(F) [11]. In a study conducted in Andhra Pradesh by Mittra et al, about 80 per cent of the respondents reported that the ANMs were providing health education related to antenatal care, intranatal care, postnatal care and nutrition [12]. In the present study, only $93(8.3 \%)$ families were visited by the MPHW(F) on occasional basis, while rest of the 1030 families (91.7\%) were never visited by her.

The probable reason for less visits by the MPHW(F) in the present study could be that she was present at the subcentre providing services to people and was more dependent on the ASHA for home visits and visited the families only occasionally, when it became absolutely necessary in high risk cases.

According to a study done by Kaur et al in rural parts of Amritsar (2015), only $1.8 \%$ of the total families were ever visited by MPHW(M) [11]. A study conducted in the primary health centre and subcenters in Kanbha, Ahemdabad district, Gujarat by Shah et al (2015) on the working of the $\operatorname{MPHW}(M)$, revealed that the maximum time $(30.17 \%)$ was spent by doing non work-related activities by the MPHW(M), followed by the time spent during the lunch breaks $(17.8 \%)$, reports writing $(10.87 \%)$ and traveling $(10.13 \%)$, and minimum time was spent on health related services $(0.96 \%)$ such as field activity, home visits and immunization.
The study also further showed that none of the MPHWs male were able to define their job responsibilities. Similar results were seen in the present study as well; where despite of having the post of MPHW(M) filled, he was not visiting the houses on a periodic basis which could be due to the lack of supervision [13].

A study conducted on the role of anganwadi workers in Mysore district in 2013 showed that all the anganwadi workers distributed packed nutritious food to the pregnant mothers identified by the anganwadi workers. The frequency of supply of food items was once in a month as told by 60 percent respondents, wherein 35 percent responded that food was supplied once in 25 days and another five percent reported once in 15 days [14]. According to a study done in rural parts of eastern India by Sahoo et al (2016), supplementary nutrition did not meet their demands with supply of only eight eggs per month by the anganwadi workers, which was very less [15].

According to a study done by Thomas et al (2015) in anganwadi centres in Ludhiana, it was seen that the coverage of the services and attendance in the anganwadi centres was low for children (11.3\% only) and nil for pregnant women, lactating mothers and adolescent girls. Also, the provision of supplementary nutrition to the beneficiaries was inadequate [16].

According to the present study, distribution of food items was irregular and occasional which was a major reason for dissatisfaction among the population. The probable reason could be the irregular and less disbursement of funds and supplies from the government to the anganwadi centres, due to which they were unable to distribute the food on timely basis.

\section{Limitations}

In the present study, the eldest adult member who was present at the time of the visit was taken as a respondent which could be considered as a limitation because males are not very familiar with the health workers specially female health workers, who mostly deal with females, adolescents and children of the house.

Increased chances of recall bias could also be present due to which exact number of visits and duration between each visit could not be conveyed by the respondent. 


\section{Conclusion}

The present study concluded that the home visits by the multipurpose health workers was very less, probably because their services were more concentrated at the level of the subcentre; while ASHA still contributed towards the home visits, though on an occasional basis. The main reasons cited for the visits by the ASHA were immunization of children, $\mathrm{MCH}$ related activities and for the treatment of minor ailments.

Most of the families were aware about the existence of Anganwadi centre in the village; however majority of them reported that the food availability at the centre was occasional and mostly irregular. ASHA and Anganwadi worker being the peripheral level workers, play an important and imperative role in providing the primary health care services to the rural community and for motivating people to utilize the existing health services.

The primary health care workers can make a valuable contribution to the community development by improving access to and coverage of the community with basic health services which would further lead to improved health outcomes, and therefore it becomes important on their part to carry out the field visits on a regular and periodic basis, for the better in-depth understanding of the health needs at the grass root level.

\section{What the study adds to existing knowledge}

There is an urgent need of supervision for the primary health care workers so that their responsibilities and activities could be analyzed and evaluated and any kind of limitations could be addressed at the grass root level. Adequate and timely supply of food items must be ensured at the Anganwadi centres so that the nutritional requirements of the population is met.

\section{Author's Contribution}

- Tejbir Singh: Idea for the study, Guiding Author, Review and final editing

- Ritika Bakshi: Data Collection (Principal Investigator), Data entry, Analysis of the data, paper writing and final editing

- Jasleen Kaur: Review of data entry and data analysis, editing at each step during paper writing
- Ankit Arora: Data analysis, reference writing and editing

- Dr. Richa Verma: Review of paper, final editing

\section{Acknowledgement}

I owe special thanks to my fellow colleagues, staff members and the respondents of village Nagkalan.

\section{Reference}

01. Saprii L, Richards E, Kokho P, Theobald S. Community health workers in rural Indiaanalysing the opportunities and challenges Accredited Social Health Activists (ASHAs) face in realising their multiple roles. Human Resources for Health. 2015;13(1)95.

[Crossref]

02. Jain N, Srivastava NK, Khan AM, Dhar N, Manon $S$, Adhish $V$, Nandan D. Assessment of functioning of ASHA under NRHM in Uttar Pradesh. Health and Population- Perspectives and Issues. 2008;31(2)132-40.

[Crossref]

03. Sarin J, Jeeva S, Geetanjli, Sheoran P. Practices of auxiliary nurse midwives regarding care of baby at birth. Nursing and Midwifery Research Journal. 2011;7(3)110-9.

[Crossref]

04. Dwivedi N, Deshmukh P, Singh S, Dongre A, Dey D, Kumar V, Upadhyaya S. Outworn or forgotten- Time and motion study of male multipurpose health workers from South India. The Journal of Community Health Management. 2017;4(4)156-63.

[Crossref]

05. Dayal MS. Integrated child development services. Health and Population- Perspectives and Issues. 1979;2(1)80-3.

[Crossref]

06. Garg PK, Bhardwaj A, Singh A, Ahluwalia SK. An evaluation of ASHA worker's awareness and practice of their responsibilities in rural Haryana. Natl J Community Med. 2013;4(1)76-80. [Crossref]

07. Bapai $\mathrm{N}$ and Dholakia $\mathrm{H}$. Improving the performance of Accredited Social Health Activists in India (Working Paper No-1). 2011[updated 2011Jan; cited 2019 Nov 02]. Available from: [Article] [Crossref] 
08. Singh MK, Singh JV, Ahmad N, Kumari R, Khanna A. Factors influencing utilization of ASHA services under NRHM in relation to maternal health in rural Lucknow. Indian journal of community medicine- official publication of Indian Association of Preventive \& Social Medicine. 2010;35(3)414.

[Crossref]

09. NFHS-4, State Fact Sheet Punjab. 2015. Available from: [Article] [Crossref]

10. National Family health survey 2015-16, Punjab. Available from: [Article] [Crossref]

11. Kaur B, Deepti SS, Mahajan S. Knowledge, Attitude and Practices Assessment of Rural Population towards Public Health Facilities in Amritsar District. International Journal of Health Sciences and Research (IJHSR). 2015;5(2)32-6. [Crossref]

12. Mittra P, Nair KS, Gandotra R. A study of client satisfaction with services provided by subcentres in two districts of Andhra Pradesh. Perspectives and Issues. 2000;23(2)84-94.

[Crossref]
13. Shah AG, Davda B, Parikh S, Bala DV. Timemotion study of the multipurpose health worker in the primary health center and subcenters in Kanbha, Ahmedabad district, Gujarat. Int J Med Sci Public Health. 2016;5;142-5.

[Crossref]

14. Sandhyarani MC, Rao CU. Role and responsibilities of anganwadi workers, with special reference to Mysore district. Int J Sci Environ Tech. 2013;2(6)1277-96. [Crossref]

15. Sahoo J, Mahajan PB, Paul S, Bhatia V, Patra AK, Hembram DK. Operational Assessment of ICDS Scheme at Grass Root Level in a Rural Area of Eastern India- Time to Introspect. J Clin Diagn Res. 2016;10(12)LC28-32.

[Crossref]

16. Thomas N, Sengupta $\mathrm{P}$, Benjamin AI. An Assessment of the Integrated Child Development Services Programme in an Urban Area of Ludhiana, Punjab. Research Gate. [updated 2015 Mar; cited 2019 Nov 02]. Available from: [Article] [Crossref] 